\title{
Lung cancer trends: smoking, obesity, and sex assessed in the Staten Island University's lung cancer patients
}

This article was published in the following Dove Press journal:

International Journal of General Medicine

2 July 2014

Number of times this article has been viewed

\section{Shilpi Gupta' \\ Samer Hassan' \\ Vijaya R Bhatt ${ }^{2}$ \\ Houssein Abdul Sater ${ }^{1}$ \\ Asma Dilawari ${ }^{3}$}

'Hematology-Oncology, Staten Island University Hospital, Staten Island, NY, USA; ${ }^{2}$ Hematology-Oncology, Nebraska Medical Ctr, Omaha, NE, USA; ${ }^{3}$ Hematology-Oncology, MedStar Georgetown University Hospital, Olney, Maryland, USA
Correspondence: Houssein Abdul Sater Hematology-Oncology, Staten Island University Hospital, 177 Clifton Avenue, Staten Island, NY 10305, USA

Tel +l 6462044559

Email houssein.md@gmail.com, hus_ tas@hotmail.com
Introduction: The incidence of lung cancer in the United States decreased by 1.8\% from 1991 to 2005 while it increased by $0.5 \%$ in females. We assessed whether nonsmokers afflicted with lung cancer at Staten Island University Hospital are disproportionately female in comparison to national averages. We also evaluated different factors including race, histology, and body mass index (BMI) in correlation with smoking history.

Methods: A retrospective chart review was conducted from 2005 to 2011 on 857 patients. Patients were divided into two groups according to their smoking status: current or eversmokers, and former or never-smokers. A chi-square test for categorical data and multivariate logistic regression analyses was used to study the relation between BMI and the other clinical and demographic data.

Results: Forty-nine percent of patients were men and 51\% were women with a mean age at diagnosis of 67.8 years. Current smokers were most common $(50.2 \%)$ followed by ever-smokers (18.2\%), former smokers $(15.8 \%)$ and never-smokers (15.6\%). Forty eight percent had stage IV lung cancer upon presentation. Never-smokers with lung cancer were 24 times more likely to be females. However, the proportion of female former smokers (31.6\%) was lower than the proportion of male former smokers $(68.4 \%)(P=0.001)$. There was no significant association between American Joint Committee on Cancer (AJCC) stage, sex, race, and histological type in the two smoking groups. Current/ever-smokers tended to be younger at age of diagnosis $(P=0.0003)$. BMI was lower in the current/ever-smokers $\left(26.8 \mathrm{~kg} / \mathrm{m}^{2}\right)$ versus former/never-smokers $(28.8)$ in males $(P=0.0005)$. BMI was significantly higher in males $(30.26)$ versus females $(25.25)$ in the never-smoker category $(P=0.004)$. Current smokers, compared to others, had a lower BMI in males (26.4 versus $28.3 ; P=0.0001)$ and females (25.5 versus $26.9 ; P=0.013$ ) but the mean BMI for all groups was in the overweight/obese range.

Conclusion: Our population of lung cancer patients although demographically distinct, reflects a similar proportion of afflicted nonsmokers to the national population. Smoking is a major risk factor for lung cancer, but there is also a possible direct correlation with BMI that would support obesity as a potential risk factor for lung cancer.

Keywords: lung, cancer, smoking, obesity, BMI, Staten Island

\section{Introduction}

Recent Centers for Disease Control trends show a decline in the incidence of lung cancer in the United States by $1.8 \%$ from 1991 to $2005 .{ }^{1}$ Despite a decrease in mortality from lung cancer of about 1.9\% per year from 1993 to 2005 among men, the number of deaths in women during the past years has remained relatively unchanged until $2011{ }^{2}$ Smoking is a well-known risk factor for lung cancer, but lung cancer in non-smokers 
is also one of the leading causes of death in the United States making up about $10 \%-15 \%$ of lung cancer cases. ${ }^{3}$ A recent study by the American Association for Cancer Research (AACR) used an internet-based protocol to collect information about never-smokers with lung cancer and reported that $88 \%$ of the cases of non-smokers with lung cancer were females. ${ }^{4}$ Although stage at diagnosis and performance status impact the overall prognosis and outcomes of lung cancer patients, studies have also indicated an improved survival in female non-smokers and a possibility that the biology of these tumors may be unique. ${ }^{5}$

There is little literature studying the differences in lung cancer trends in female smokers versus non-smokers, or female non-smokers versus male non-smokers. Most studies evaluating non-smokers with lung cancer include a diverse population of subjects and this adds many variables to the analyses of non-smokers versus smokers. In our clinical setting we serve a population with relatively homogeneous socioeconomic levels and environmental exposures. Examining a small cohort of such patients with lung cancer could lend further support to the finding that non-smokers with lung cancer are disproportionately female and has the advantage of reducing confounding factors in drawing this conclusion. In addition, studies have also assessed associations between lung cancer and other risk factors such as obesity. A recent meta-analysis showed an inverse correlation between BMI and lung cancer incidence especially in current and former smokers. ${ }^{6,7}$

\section{Aims and objectives}

Our objective was to perform a retrospective chart review of patients diagnosed with lung cancer, separate non-smokers with lung cancer, and further stratify these patients based on smoking status in order to assess our population on Staten Island. We also aimed to assess whether non-smokers afflicted with lung cancer in our population were disproportionately female. We also studied the relation between weight, smoking, and lung cancer.

\section{Patients and methods}

We performed a retrospective chart review of 857 patients from 2005 to 2011. We divided the population into four groups according to their smoking status: current smokers (active or quit $\leq 1$ year), ever-smokers (quit $>1$ year but $\leq 15$ years), former smokers (quit $>15$ years ago) and never-smokers. We also evaluated different factors including race, tumor histology, and body mass index (BMI) and examined their correlation with smoking history.
The association between sex, American Joint Committee on Cancer (AJCC) stage, tumor histologic type, and smoking status were tested using the chi-square test. A chi-square goodness of fit test was used to test the rate of smoking/ non-smoking among lung cancer cases at our institution to the rate for United States reported by the AACR.

For continuous endpoints (BMI, age at diagnosis), the Mann-Whitney test was used to determine whether there was a difference between smoking groups on the variables of interest (BMI, age at diagnosis).

\section{Results}

We reviewed 857 charts of which 416 (48.5\%) were men and $441(51.4 \%)$ were women. Most of the study population was Caucasian $94.98 \%$ and $2 \%$ was African-American. The mean age at diagnosis was 67.82 (standard deviation \pm 10 ) years. Forty-eight percent of the patients had stage IV lung cancer at the time of diagnosis. Current smokers were most common (50.29\%), followed by ever-smokers (18.2\%). Former and never-smokers accounted for $15.87 \%$ and $15.64 \%$, respectively, of the study population.

There was a significant association between smoking status and sex. Never-smokers with lung cancer were 24 times more likely to be females. However, the proportion of female former smokers (31.62\%) was significantly lower than the proportion of male former smokers $(68.38 \%)$ with a $P$-value of $<0.0001$.

We divided the population into two groups: former and never-smokers versus current and ever-smokers (Table 1). There was no significant association between AJCC stage and sex or smoking status. There was no statistically significant

Table I Difference in BMI, race, age, AJCC stage and histology type in different smoker groups

\begin{tabular}{|c|c|c|c|}
\hline Smoking status & Current/ever & Former/never & $P$-value \\
\hline Mean BMI kg/m² (male) & 26.8 & 28.8 & 0.0005 \\
\hline Mean BMI kg/m² (female) & 26.4 & 26.01 & 0.66 \\
\hline $\begin{array}{l}\text { Smoking distribution in } \\
\text { different age group }\end{array}$ & & & 0.0003 \\
\hline Between $50-75$ years & $426(52.79 \%)$ & 167 (20.69\%) & \\
\hline Older than 75 years & 125 (I5.49\%) & 89 (11.03\%) & \\
\hline Race & & & 0.3391 \\
\hline Caucasian & $561(95.57 \%)$ & $253(93.7 \%)$ & \\
\hline African American & II (I.87\%) & $5(1.85 \%)$ & \\
\hline AJCC stage & & & 0.977 \\
\hline Stages I and II & $119(15.76 \%)$ & $55(7.28 \%)$ & \\
\hline Stages III and IV & $398(52.72 \%)$ & $183(24.24 \%)$ & \\
\hline Histology type & & & 0.151 \\
\hline Non-small-cell lung cancer & 345 (40.3\%) & 154 (I7.99\%) & \\
\hline Small-cell lung cancer & $205(23.95 \%)$ & $88(10.28 \%)$ & \\
\hline
\end{tabular}

Abbreviations: BMI, body mass index; AJCC,American Joint Committee on Cancer. 
difference in the race or the histologic type (small-cell lung cancer [SCLC] versus non-SCLC [NSCLC]) in both groups. Comparison based on differentiation of tumor (squamous cell versus adenocarcinoma of the lung) in relation to smoking or age wasn't performed.

We also noted that the smoking pattern changed as people aged. A significantly greater proportion (77\%) of the current/ ever-smokers were between 50 and 75 years old compared to $65 \%$ in the former/never smokers group $(P<0.0003)$. Additionally there were more patients older than 75 years in the former/never-smokers group (35\%) compared to current/ ever-smoker group (23\%) $(P<0.0003$; Table 1$)$.

Analysis of variance revealed that BMI was significantly higher in males versus females $(P<0.002)$. Further analysis showed a significantly higher BMI in males $\left(30.26 \pm 1.67 \mathrm{~kg} / \mathrm{m}^{2}\right)$ versus females $\left(25.25 \pm 0.52 \mathrm{~kg} / \mathrm{m}^{2}\right)$ in the never-smoker category $(P<0.0044$; Figure 1$)$. In men there was also a significant difference in BMI between both smoking groups $\left(26.8 \mathrm{~kg} / \mathrm{m}^{2}\right.$ in the current/ever-smokers versus $28.8 \mathrm{~kg} / \mathrm{m}^{2}$ in the former/never-smokers group) $(P<0.001$; Table 1). The male current smokers with lung cancer had a lower BMI than all the other groups of men $(P<0.001$; Table 2). Never-smoker males in particular had a higher BMI $\left(30.2 \mathrm{~kg} / \mathrm{m}^{2}\right)$ compared to the other groups $\left(27.2 \mathrm{~kg} / \mathrm{m}^{2}\right)$, but this was not statistically significant. In women, there was no significant difference in the BMI in the former/never-smoker group compared to the current/ever-smoker group but women in the current smokers group tended to have a lower BMI $\left(25.57 \mathrm{~kg} / \mathrm{m}^{2}\right)$ compared to the other groups $\left(26.8 \mathrm{~kg} / \mathrm{m}^{2}\right)$ $(P<0.013)$. Patients weren't further evaluated for presence of diabetes or any metabolic syndrome in relation to lung cancer, and this could be also a subject for further studies.

\section{Discussion}

The majority of lung cancer cases worldwide are related to smoking. This was evident in our institution where $84.4 \%$ of the patients have a history of smoking. It is well-known that smoking accelerates the malignant transformation of the cells. ${ }^{8}$ Also, smokers are younger at the age of lung cancer diagnosis than non-smokers. We had an equal distribution of males and females and the majority of our patients were Caucasian, which reflects the demographics of Staten Island residents in particular. Females accounted for $91 \%$ cases of nonsmokers in our group of lung cancer patients which is similar to the national statistics $(88 \%) .{ }^{4}$ Smoking is a major risk factor for SCLC. Interestingly, there was no difference in the distribution of smoking pattern among patients with SCLC (Table 1). We attribute this finding to the high number $(\mathrm{n}=88)$ of patients found in the (former/never) group. This could be explained by the high incidence of secondhand smoking in our population and by the fact that former smokers $(n=30)$ had a median 35 pack-year history of smoking.

BMI as a function of sex and smoking status

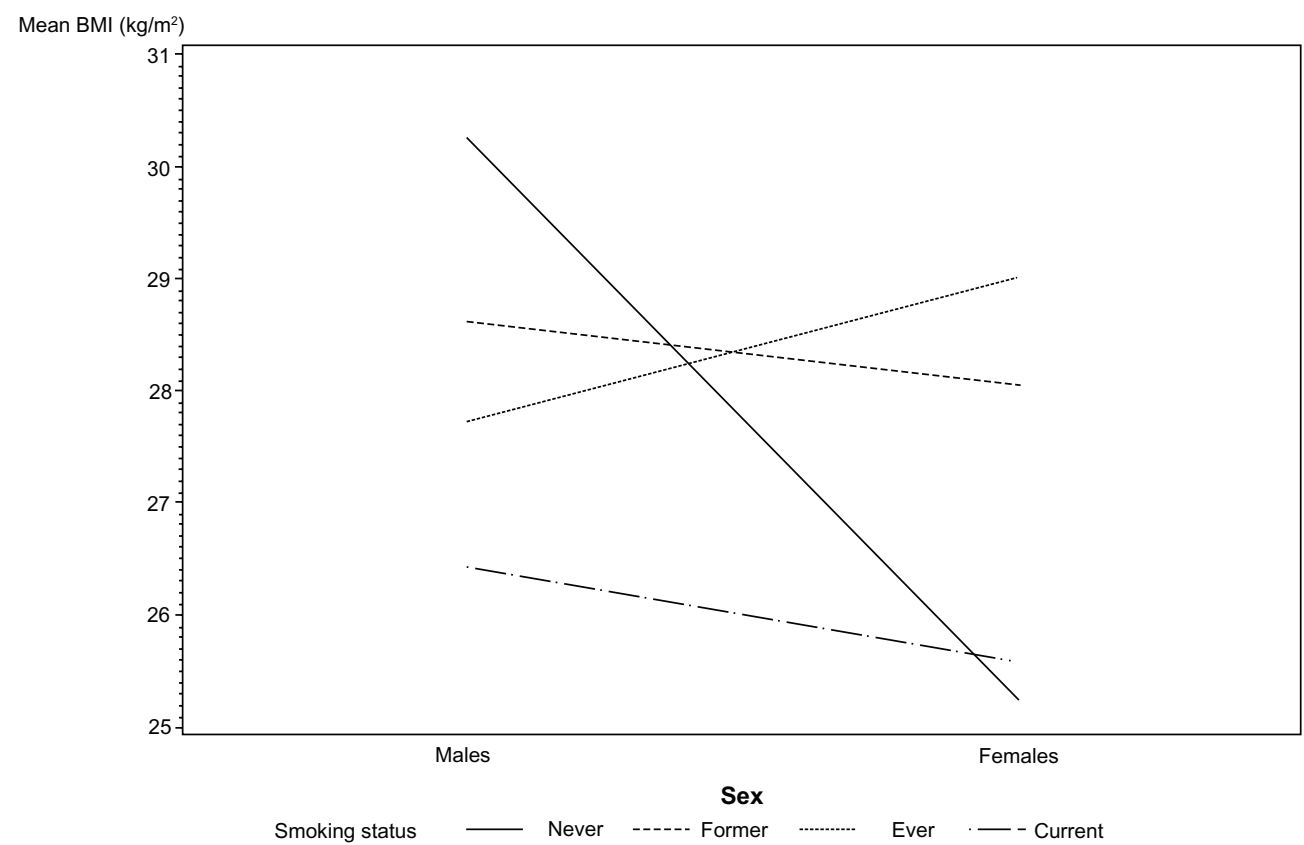

Figure I Body mass index (BMI) difference in different smokers groups in both sexes.

Notes: Females tend to have lower BMI than males in all smoking categories, except for ever-smokers (though the difference is not significant), where females have higher BMI than males. The significant difference is in the never-smoking groups. 
Table 2 Current smokers' body mass index (BMI) compared to others

\begin{tabular}{|c|c|c|}
\hline Sex & Male & Female \\
\hline \multicolumn{3}{|l|}{ Smoking groups } \\
\hline $\begin{array}{l}\text { Mean BMI }\left(\mathrm{kg} / \mathrm{m}^{2}\right) \text { current smokers } \\
\text { versus never-, former, and ever- } \\
\text { smokers }\end{array}$ & $\begin{array}{l}26.4 \text { versus } 28.3 \\
(P<0.000 I)\end{array}$ & $\begin{array}{l}25.5 \text { versus } 26.9 \\
(P<0.013)\end{array}$ \\
\hline
\end{tabular}

Notes: Smoking is an important confounding factor and has an effect on the BMI distribution among both sexes.

Although recent studies postulated an inverse correlation between BMI and the incidence of lung cancer among men and women especially in the current smokers group, ${ }^{5}$ in our study, the mean BMI in all groups is in the overweight/ obese range regardless of their smoking status. Current smokers tended to have a lower BMI compared to the other groups in both men and women with a mean BMI of 26.43 and $25.57 \mathrm{~kg} / \mathrm{m}^{2}$ respectively. Recently, it has been proven that smoking induces the over-expression of the AZGP1 (alpha-2-glycoprotein 1) gene in the airways epithelial cells of smokers. This gene is involved in lipolysis and fat loss. ${ }^{9}$ Smoking may be a possible confounding factor in the evaluation of weight and lung cancer.

It has been postulated that excess weight affects the metabolism of sex hormones, immune responses, and oxidative stress. Chronic hyperinsulinemia, due to excess weight, is implicated in the pathogenesis of several cancers. ${ }^{10}$ In vitro studies demonstrated that insulin and insulin-like growth factor (IGF)-1 induce cell proliferation and inhibit apoptosis. ${ }^{11}$ Adipocytokines inhibit leukocyte migration and enhance the tumor proliferation, invasion, and metastasis. ${ }^{11}$ Recent studies highlight the role of adipose tissue in immune dysfunction and carcinogenesis. IGF-1 also affects the synthesis and the biological activity of sex steroids. ${ }^{12,13}$

Estrogen may play an important role in lung carcinogenesis among nonsmokers. ${ }^{14}$ Estrogen is synthesized in situ via aromatase in both sexes and females maintain higher levels of estrogen even after menopause. It acts through the estrogen receptor beta to promote malignant cell proliferation and potentiate the effect of IGF-receptor 1 in NSCLC. ${ }^{15}$ Some studies have even demonstrated the antitumor activity of aromatase inhibitors in NSCLC. ${ }^{16}$ Others demonstrated a link between estrogen genetic polymorphism variation and lung carcinogenesis among non-smokers. ${ }^{17}$ These factors, and the fact that more men than women are smokers ${ }^{18}$ may explain the disproportionate number of female never-smokers with lung cancer.

We are already aware of adipose tissue promoting androgen conversion to estrogens. Perhaps the higher BMI seen in the small number of male never-smokers in our group should be explored in a larger study as well.

\section{Conclusion}

Despite the new modalities of cancer therapy, lung cancer remains the leading cause of cancer death worldwide as the majority of cases present with advanced stage (48.6\% in our study). There has been a decrease in the incidence of lung cancer attributed to the decreased incidence of smoking. ${ }^{2}$ Further studies are needed to explore the role of other risk factors. Our study confirms interesting reports of the links between obesity and sex and their role in the incidence of this disease in patients without a smoking history.

There is clear association between obesity and some types of cancers like colon cancer, postmenopausal breast cancer, endometrial, and pancreatic cancer. ${ }^{19}$ This relationship is still inconclusive in lung cancer. While some studies demonstrate an inverse association between lung cancer and obesity, others demonstrate a positive association in former and never-smokers.

Our study has demonstrated that our population of lung cancer patients reflects a similar proportion of afflicted nonsmokers as compared to the national population. These patients involved in our study were predominantly Caucasians and this reflects the demographic nature of Staten Island. The study shows a possible direct relationship between BMI, smoking history, and lung cancer and these findings warrant further evaluation. Assessing further parameters such as diabetes mellitus or metabolic syndrome in relation to lung cancer especially in the nonsmokers group might add to our data and warrants further studying.

\section{Disclosure}

The authors report no conflicts of interest in this work.

\section{References}

1. Jemal A, Thun MJ, Ries, et al. Annual Report to the Nation on the Status of Cancer, 1975-2005, featuring trends in lung cancer, tobacco use, and tobacco control. J Nat Cancer Inst. 2008;100(23):1672-1694.

2. Centers for Disease Control. State-specific trends in lung cancer incidence and smoking - United States, 1999-2008. MMWR. Morbidity and Mortality Weekly Report. 2011;60(36):1243-1247.

3. Jemal A, Murray T, Ward E, et al. Cancer statistics, 2005. CA Cancer J Clin. 2005;55(1):10-30.

4. Girard N, Lou E, Azzoli CG, et al. Analysis of genetic variants in neversmokers with lung cancer facilitated by an Internet-based blood collection protocol: a preliminary report. Clin Cancer Res. 2010;16(2):755-763.

5. Nordquist LT, Simon GR, Cantor A, Alberts WM, Bepler G. Improved survival in never-smokers vs current smokers with primary adenocarcinoma of the lung. Chest. 2004;126(2):347-351.

6. Yang Y, Dong J, Sun K, et al. Obesity and incidence of lung cancer: a meta-analysis. Int J Cancer. 2013;132(5):1162-1169. 
7. Smith L, Brinton LA, Spitz MR, et al. Body mass index and risk of lung cancer among never, former, and current smokers. J Natl Cancer Inst. 2012;104(10):778-789.

8. Hecht SS. Lung carcinogenesis by tobacco smoke. Int $J$ Cancer. 2012;131(12):2724-2732.

9. Vanni H, Kazeros A, Wang R, et al. Cigarette smoking induces overexpression of a fat-depleting gene AZGP1 in the human. Chest. 2009;135(5):1197-1208.

10. Lawlor MA, Alessi DR. PKB/Akt: a key mediator of cell proliferation, survival and insulin responses? J Cell Sci. 2001;114(Pt 16): 2903-2910.

11. Lang K, Ratke J. Leptin and Adiponectin: new players in the field of tumor cell and leukocyte migration. Cell Commun Signal: CCS. 2009;7:27

12. Key TJ, Allen NE, Verkasalo PK, Banks E. Energy balance and cancer: the role of sex hormones. Proc Nutr Soc. 2001;60(1):81-89.

13. Key TJ, Appleby PN, Reeves GK, et al. Body mass index, serum sex hormones, and breast cancer risk in postmenopausal women. $J$ Natl Cancer Inst. 2003;95(16):1218-1226.
14. Verma MK, Miki Y, Sasano H. Aromatase in human lung carcinoma. Steroids. 2011;76(8):759-764.

15. Tang H, Liao Y, Chen G, et al. Estrogen upregulates the IGF-1 signaling pathway in lung cancer through estrogen receptor-beta. Med Oncol. 2012;29(4):2640-2648.

16. Miki Y, Suzuki T, Abe K, et al. Intratumoral localization of aromatase and interaction between stromal and parenchymal cells in the nonsmall cell lung carcinoma microenvironment. Cancer Research. 2010;70(16):6659-6669.

17. Chua HW, Ng D, Choo S, et al. Effect of MDM2 SNP309 and p53 codon 72 polymorphisms on lung cancer risk and survival among nonsmoking Chinese women in Singapore. BMC cancer. 2010;10:88.

18. Thun MJ, Henley SJ, Burns D, Jemal A, Shanks TG, Calle EE. Lung cancer death rates in lifelong nonsmokers. J Natl Cancer Inst. 2006;98(10):691-699.

19. Fair AM, Montgomery K. Energy balance, physical activity, and cancer risk. Methods Mol Biol. 2009;472:57-88.
International Journal of General Medicine

\section{Publish your work in this journal}

The International Journal of General Medicine is an international, peer-reviewed open-access journal that focuses on general and internal medicine, pathogenesis, epidemiology, diagnosis, monitoring and treatment protocols. The journal is characterized by the rapid reporting of reviews, original research and clinical studies across all disease areas.

\section{Dovepress}

A key focus is the elucidation of disease processes and management protocols resulting in improved outcomes for the patient.The manuscript management system is completely online and includes a very quick and fair peer-review system. Visit http://www.dovepress.com/ testimonials.php to read real quotes from published authors.

Submit your manuscript here: http://www.dovepress.com/international-journal-of-general-medicine-journal 